\title{
REFLEXIONES ENTORNO A LOS USOS DEL LENGUAJE EN CONTEXTOS ANALÓGICOS Y DIGITALES
}

Prof. Elba Meana (*)

$\mathrm{E}$ 1 cambio cultural en la concepción del saber es inminente. Los desafíos en materia de alfabetización digital hacen cada vez más urgente la necesidad de acortar la brecha digital en los procesos de gestión y promoción del conocimiento. Asimismo, La Didáctica de la Lengua ve cada vez más ampliados sus horizontes de expectativa a medida que las TIC avanzan: nuevas maneras de leer y de escribir surgen entonces, y por tanto, nuevas formas de intervención docente se presentan por ahora en un escenario con escaso público. Aquí surge el tema de esta ponencia, ¿qué condicionantes imponen las nuevas tecnologías a los usos del lenguaje?

¿Qué lugar de poder, ocupará ahora el conocimiento científico, que ya, de suyo, se sabe, es, además, provisional? Si la Modernidad buscó interpretar el pensamiento del autor; si luego, y gracias a la Física Cuántica, este lugar se trasladó tanto al texto como al lector; y si los últimos estudios sobre la lectura la han desplazado hacia miradas más etnográficas, hacia prácticas sociales situadas/inclusivas; este siglo XXI, festeja con fanfarrias el advenimiento del "discurso antrópico", aquél en el que el alumno lector, más solitario que nunca construye según su leal saber y entender sus propios significados, atribuye en absoluto aislamiento sentidos posibles a sus interpretaciones, cada vez más fragmentarias y descontextualizadas, sentado frente a una máquina de luces y silencios.

Pensar en la posibilidad de instalar las TIC en el Sistema Educativo, en cualquiera de sus niveles, requiere reconocer aún a una escuela tradicional, propia del Racionalismo, de carácter representacionista, donde existe una concepción de la realidad como externa y objetiva. Con el hipertexto las lógicas tradicionales se desequilibran. Es el uso del "Discurso discurrido". Es la lectura del TEXTO DE HECHO, almacenado en forma digital. Lyotard va más allá aún de este análisis de superficie cuando señala en "La Condición Posmoderna" (1998), que el problema "no es una mera cuestión de tecnología, sino una cuestión cultural”.

Desde este espacio se propone debatir, y, por cierto, poner en el escenario ante público más numeroso e interesado el desafío de intentar nuevos acercamientos más plurales y situados de las prácticas de lectura y escritura a través de un currículum (wac) compartido, interdisciplinario, en donde el estudiante es provisoriamente dependiente del docente en la construcción de sus propios procesos de transformación del conocimiento. Debatir y multiplicar experiencias en este sentido sería una muy buena razón para convocarnos.

(*) Docente JTP de Competencias Lingüístico-Comunicativas - Facultad de Ciencias Exactas Naturales y Agrimensura.U.N.N.E.-meana_elba_ester@hotmail.com 
"Leer y escribir son prácticas novedosas y desafiantes para los alumnos porque difieren de los modos de lectura y escritura en la secundaria".

Dra. Paula Carlino. "XII Congreso para el Desarrollo de la lectura y la escritura. IV Foro de Literacidad y aprendizaje”. Méjico, 19/9/2013.

\section{Las TIC, caminos transitados y nueva agenda}

Esta propuesta se funda en una mirada del docente como un profesional reflexivo, que, haciendo uso de su "racionalidad interpretativa”, en términos de Schön ${ }^{1}$ (1998), construye para sus alumnos consignas que le permitan acortar la brecha digital en la generación del conocimiento, fundado en la aceptación de la incertidumbre y la complejidad, y de la provisoriedad de la ciencia, a diferencia del simple procesamiento de la información, que se funda en la certeza y en un concepto de ciencia como un saber acabado.

A partir de las TIC las fronteras se ensanchan, se desdibujan: habrá que pensar en nuevos formatos y dispositivos, en consignas acordes con la virtualidad, que no es la no presencia, ni tampoco la transformación de una realidad en un conjunto de posibles, sino la redistribución de los objetos de estudio, sus inevitablemente diferentes formas de abordaje, que sitúan la clase en espacios $\mathrm{y}$ tiempos diferentes.

La abundancia de la información más la igualdad de oportunidades que ofrecen las $T I C$, abren nuevos interrogantes, $y$, delinean, al mismo tiempo, segura y pausadamente, tan- to nuevos como desafiantes trazos en el paisaje educativo. Todo ello, a partir de las nuevas herramientas que la actual Política Educativa (entendiendo aquí el enunciado: "política" en el sentido extenso de su acepción) difunde y promueve, a través de importantes consensos plasmados en Resoluciones del CFE y sus respectivos Anexos. Una palmaria muestra de estos últimos, lo constituyen, por ejemplo, los Boletines informativos, la misma página web del Ministerio de Educación de la Nación y también de las distintas Provincias argentinas, el Canal encuentro, las Convocatorias Nacionales a participar de Proyectos comunes en todas las provincias, las capacitaciones docentes del Programa de Conectar- Igualdad, las convocatorias y Congresos promovidos desde las Universidades para poner en escena las nuevas Tecnologías de la información y comunicación.

Así surgen las TIC como un interesante dispositivo tendiente a coadyuvar a la disminución de la extendida brecha preexistente en la sociedad; resultando de este modo, una posible respuesta, si no la única, sí al menos uno de los caminos más habilitados por donde empezar a trazar posibles ingenierías de acción no solo factibles, como se ha dicho, sino también de previsibles resultados positivos.

Dicho esto en razón de, 1) la importante inversión tanto en recursos materiales como así también humanos puestos en idéntica dirección: disminuir la brecha en el terreno de las inocultables diferencias en calidad educativa a lo largo y ancho de nuestro país. 2) El andamiaje que se ha construido como dispositivo para instalar esta herramienta

\footnotetext{
${ }^{1}$ Schön, D. (1998):"El profesional reflexivo. Cómo piensan los profesionales cuando actúan”. Barcelona, Paidós Ibérica
} 
hacia el interior de las Instituciones Educativas, el seguimiento/monitoreo, y el acompañamiento de los especialistas contratados a tal fin. Tanto el apartado 1) como el 2), con la finalidad de tornar más asequibles estos recursos, que, se sabe, habrán de demandar un tiempo prudencial para instalarse cómodamente en territorio educativo, un lugar de tradición, cuyo entretejido tanto ha sostenido los vaivenes sociales/ económicos/culturales, como así los pedagógicos; esos mismos, que ahora están siendo puestos bajo la lupa.

Cabría en este sentido formularse la pregunta de si podrán las TIC desarrollar las potencialidades necesarias para que esta brecha se angoste, o, si simplemente serán neutralizadas por las formas tradicionales de concebir el saber en las Instituciones Educativas, Esto es: si podrán constituirse en un concreto factor de cambio.

Sería aventurado predecir una respuesta. Sin embargo, caben resaltar varios aspectos a favor: Según el Centro de Estudios de Políticas Públicas (septiembre, 2.006), en: "Modelos de Formación Continua en América Latina", durante la década de los noventa, la agenda educativa ha pasado por un modelo de "capacitación docente" ligada a la difusión curricular, donde el docente ha sido siempre el "receptor de conocimientos" (subyace aquí la idea de un docente como sujeto de déficit), con la carga peyorativa que este enunciado entraña.

La nueva agenda de la presente década está orientada a:

1) Recuperar las experiencias educativas docentes como una forma de reconstrucción de la tradición crítica fenomenológica. A través por ejemplo, de las relatorías, participación en foros de actualización, aprendizaje cooperativo y orientado.
2) Promover nuevos desafíos desde propuestas centradas en toda la institución, el intercambio entre colegas de experiencias positivas. Principio fundamental: trabajo horizontal y colaborativo, que se da en llamar "conocimiento de la práctica", dejando atrás la consabida división. "teoría/práctica"

3) Redes de información e intercambio para el desarrollo profesional docente, mucho más abarcador que la pretérita denominación: "capacitación docente". (Resolución del CFE Nro 30/07, Anexo 2, Cap $\mathrm{V}$, Inc 39).

4) Contrucción de formatos como el de Conectar- Igualdad, en donde lo aprendido permite incidir/impactar directamente en las condiciones en las que se llevan a cabo las prácticas de enseñanza en las escuelas.

5) Concebir el Desarrollo Profesional en razón de las reales necesidades de las Instituciones. En este caso, el imperativo de la Alfabetización digital para todos es un imperativo pedagógico, cuya base está centrado en una demanda proveniente tanto de las Instituciones, que necesitan adaptarse al nuevo curso de los tiempos, como de la sociedad misma que requiere más que nunca de un Sistema Educativo que dé respuestas, y, sobre todo PREGUNTAS, acerca del controvertido panorama educativo que estamos transitando.

\section{La brecha digital: el doble desafío de la lec- tura y la escritura digital}

Pretender que los alumnos se familiaricen con las formas más idóneas de buscar información en las Redes Sociales, suministrándoles solamente unos pocos criterios de orientación no es aconsejable. 
La búsqueda de las lecturas más autorizadas se inician siendo primeramente seleccionadas por el propio docente. Es entonces cuando, se analiza con los alumnos los requerimientos indispensables de todo material de consulta. Ellos son: 1) Autoridad. 2) Actualización. 3) Navegabilidad. 4) Organización. 5) Selección de contenidos. 6) Adecuación al destinatario.

Se considera que no es posible que los alumnos indaguen por sí mismos sin tener previamente los ejemplos CONCRETOS de lo que deben realizar. Los alumnos se iniciarán siendo "DEPENDIENTES" de actividades modélicas ya realizadas. Ellos luego replicarán los procedimientos una vez recorridos estos trayectos.

Dichos protocolos incluyen la conversación y mostración previa del trabajo por realizar, con el objetivo de que, a la hora de leer/ textualizar un Trabajo Práctico tengan en la mente los pasos sugeridos, nunca impuestos, para llevar la propuesta a buen término.

Se espera, naturalmente, que ellos luego realicen esta tarea solos.

Esta pedagogía estriba en la experiencia de haber visto tantos alumnos angustiados por tener que realizar una "Monografía" o un "Trabajo de Investigación", sin otro recurso más que una fría enumeración de pasos a seguir, entregada por el docente. De igual manera que ocurre con la elaboración de una Investigación sin estar debidamente preparados, también ocurre que se deja solos a los alumnos, con unos cuantos consejos, en la tarea de encontrar información fidedigna en Internet

La Alfabetización digital representa un doble desafío pedagógico para los estudiantes: el manejo de las estrategias cognitivas y lingüisticas de lectura y escritura propias de un texto analógico, más las herramientas digitales a ejercitar para familiarizarse con búsquedas y plataformas que no son las que ellos habitualmente manejan, aún considerando que sean habitantes nativos de Internet, a diferencia del docente, de quien se dice que es "inmigrante".

La brecha digital sigue siendo todavía importante: las instituciones educativas, generalmente a la zaga de los cambios que requiere la sociedad deberá ponerse al ritmo de los nuevos vientos que soplan. El ESTADO NACIONAL tiene una gran responsabilidad en este sentido, a la hora de asignar los necesarios presupuestos, capacitaciones, etc; garantizar, en fin, que estos aprendizajes aquí puestos en práctica sean efectivamente democratizados y puedan llegar a los sectores más necesitados de la sociedad.

Estos tiempos y espacios nuevos que aquí se proponen, requieren pensar el texto digital no como texto virtual en el sentido tradicional del enunciado, sino como un acto permanente de creación, de construcción infinita de múltiples hipertextos, polifonías, intertextos; allí donde leer y escribir supone, el manejo certero de nuevas lógicas de organización de la información y de gestión del conocimiento y de los actos de lectura y escritura.

No es una lógica de subordinación a lo tecnológico, tampoco de dominación; sino de negociación con la cultura de la tecnología puesta al servicio de un aprendizaje que se impone necesariamente diferente.

En este sentido se requiere de parte del docente un rol cada vez más profesionalizante y crítico. El necesario desarrollo de competencias vinculadas con la lectura y la escritura requieren de un sujeto de aprendi- 
zaje cada vez más activo, que sea capaz de interactuar retóricamente con los contenidos del texto.

Estos contenidos pueden ser de tres clases:

1) Contenidos en acción: los que se enseñan y aprenden en los actos de lectura y escritura concretos, situados, trabajados con finalidad específica. Por ejemplo: resumir, tomar notas, detectar problemas en la revisión de un escrito.

2) Contenidos objetos de sistematización: los que aparecen como objeto de reflexión frente a problemas que la lectura y la escritura plantean y que deben constituirse en herramientas de revisión de la producción. Tal el caso de dificultades de coherencia/cohesión textuales.

3) Contenidos tematizados: los que surgen de las necesidades del acto de escritura y que no serán sistematizados en ese momento. Problemas de gramática textual, de recuperación de referencias, uso de macrorreglas pueden considerarse contenidos tematizados.

No es vano señalar en este punto que, desde esta propuesta, se considera que tales contenidos pueden perfectamente ser enseñados y aprendidos desde todos los campos del saber, y que las herramientas que aquí se proponen van más allá del área que corresponde a Lengua, extendiéndose a todas las disciplinas.

Antes de la escritura no existió una forma definida de registrar los sucesos, leyes, victorias militares, sentimientos de un pueblo. La escritura hizo tangible la voz, permitió guardar físicamente la palabra, nacieron así las bibliotecas y el conocimiento humano pudo ser desarrollado y transmitido.

La escritura permitió independizar el habla de la persona, posibilitó ese distanciamiento (que tan bien analizan Daniel Cassany, Marina Cortés y Maite Alvara$\mathrm{do}^{2}$ ) entre la persona y su discurso. Este necesario alejamiento entre el escritor y el texto permitió tratar a la palabra como un objeto que está allí afuera, susceptible de ser analizado una y cien veces. Permitió revisar críticamente las ideas, transformarlas.

El texto digital permite una mayor descontextualización del texto; Se puede, por ejemplo, ir abriendo varias ventanas al momento de la redacción. Esa mayor despersonalización del escritor frente a la composición hace a quien escribe recorrer infinitos senderos impensados en la escritura analógica, así como también serán ilimitados los caminos que un lector habrá de recorrer como descodificador de textos. Se trata ahora de un lector o escritor que ha roto las barreras del tiempo, del espacio, de las diferencias culturales y hasta económicas, que ahora nos permiten estudiar en zonas rurales o lejos de los centros o polos culturales, allí donde antes se hacía inevitable estar para aprender.

La aparición de Internet no ha hecho más que darle rapidez y precisión a los mecanismos de revisión al permitir copiar, eliminar, justificar, alinear, cambiar de ubicación los párrafos, entre tantas competencias mecánicas que su uso permite al usuario. Quien escribe en forma digital, metafóricamente hablando "desaparece" aún más que en la escritura analógica; su despersonalización requiere de unas ciertas competencias notoriamente diferentes.

${ }^{2}$ C.f.r bibliografía al final. 
La linealidad, típica del texto cerrado analógico, da paso al texto abierto que se abre en el formato digital; el trabajo con el hipertexto, recorriendo una diversidad de itinerarios. Por ejemplo el trabajo en las plataformas, en blogs, la participación en foros, la escritura colaborativa.

En cambio, en un documento analógico las palabras permanecen más ocultas o escondidas porque las referencias son retroactivas, $y$, en todo caso, nos remiten al autor de una frase o hecho que se está tratando; además, se infiere que el contenido es propio del autor del discurso, existe una sola voz. En los textos digitales las voces se multiplican; se cuenta con enlaces hiper, intra e intertextuales, donde el usuario debe saltar de un link a otro en busca de sus propósitos. En los documentos analógicos estas características son menos evidentes, la interacción es diferida, mientras que en los textos digitales es simultánea, la transmisión es instantánea.

Y ésta es la situación sobre la cual habrá que insistir ahora desde las instituciones educativas: enseñar, inspirar a los estudiantes a ponerse por detrás de sus escritos para interrogarlos retóricamente, en el desarrollo de aquellas habilidades que la máquina no puede, al menos por ahora, realizar.

Esta interrogación retórica podría ser, por ejemplo, para:
- Saber si quien escribe está diciendo exactamente lo que quiere decir, si sus enunciados son pertinentes en relación con el tema, si no habrá párrafos que reiteran la misma idea y por lo tanto hay algo que habría que eliminar.

- Si los mecanismos de coherencia y cohesión son los más adecuados; si, por ejemplo, no habrá que recuperar algún sujeto al iniciar una oración, con la finalidad de otorgarle mayor nivel de explicitación a algún concepto.

- Si las secuencias predominantes tienen los conectores indicados, si esas hojas de ruta del discurso guardan relación con la función y la trama de los textos.

- Si el destinatario, o la finalidad del trabajo por realizar exige un determinado nivel de lengua.

- O si aquí o allá vendría bien una cita o una referencia al lector, para legitimar alguna argumentación.

- Si es necesario hacer una aclaración en determinado lugar del discurso para hacer más clara la idea.

Éstas son algunas estrategias de escritura que la máquina no puede resolver por el escritor; y es justamente lo principal sobre lo que el docente habrá de insistir a la hora de enseñar y aprender los diferentes usos del lenguaje analógico y digital.

\section{BIBLIOGRAFÍA SUMARIA}

- Alvarado, M/ Cortés, M.: “La escritura: repetir o transformar". En: "Revista de Didáctica de la Lengua y la Literatura”, Año 1 № 1, 2001.

-Carlino, P.: "La escritura en el nivel superior" y "La lectura en el nivel superior”. En:” leer y aprender en la Universidad”. Buenos Aires, Fondo de Cultura Económica, 2005. Capítulos 1 y 2 respectivamente. pp 21-33 y 67-76. 
- Cassany, D.: "De lo analógico a lo digital. El futuro de la enseñanza de la composición". En: "Revista Latinoamericana de Cultura", N²1, 2000.

- Desinano, N.: "Los alumnos universitarios y la escritura académica. Análisis de un problema". Buenos Aires, Homo Sapiens, 2009.

- Steiman, J.: “¿Qué y cómo enseña la Universidad?, ¿es un problema que tiene que plantearse el docente universitario? Actas de las Primeras Jornadas de Pedagogía Universitaria. Bs As. UNSAM Edita, 2007.

\section{ALGUNOS ENLACES}

\section{-Sobre escritura colaborativa/digital}

http://ried.utpl.edu.ec/images/pdfs/vol12N2/escrituracolaborativa.pdf

- Sobre concepciones y prácticas de docentes sobre lectura y escritura:

http://red-u.net/redu/index.php/REDU/article/view/583/pdf

- Conferencia de Paula Carlino sobre lectura y escritura, Méjico, 19/9/2013.

http://www.youtube.com/watch?v=iuRnn8euQlk

- Sobre integración del lenguaje y las TIC

http://www.cerlalc.org/Escuela/secciones/pagina_3_enlaces_2.html

- Sobre enfoques: gramatical/funciones/proceso/contenido. Página de Daniel Cassany

http://www.upf.edu/pdi/dtf/daniel_cassany/enfoques.htm

- "De lo analógico a lo digital". Cassany

http://www.lecturayvida.fahce.unlp.edu.ar/numeros/a21n4/21_04_Cassany.pdf/view?searchterm=Buscar+ en+el+Sitio 